\title{
Enantioselective Synthesis of $\alpha$-tertiary Hydroxyaldehydes by Palladium-Catalyzed Asymmetric Allylic Alkylation of Enolates
}

\author{
Barry M. Trost ${ }^{\star}$, Jiayi Xu, and Markus Reichle \\ Department of Chemistry, Stanford University, Stanford, California 94305-5080.
}

\begin{abstract}
Chiral $\alpha$-tertiary hydroxyaldehydes are very versatile building blocks in synthetic chemistry. Herein, we reported the first examples of a catalytic asymmetric protocol for the synthesis of such compounds from readily available $\alpha$-halo or $\alpha$-hydroxy ketones or enol silyl ethers with excellent yields and enantioselectivity. Its synthetic utility is demonstrated in the short, efficient formal synthesis of $(S)$ oxybutynin. In this process, the chiral ligand controls with the regioselectivity as well as enantioselectivity.
\end{abstract}

$\alpha$-Hydroxyaldehydes are very versatile building blocks for the synthesis of natural products as well as clinical drugs. ${ }^{1}$ Chiral $\alpha$-hydroxyaldehydes enjoy the added benefit of being a potential source of introducing other stereogenic centers. Up to now, the access of such compounds in enantiomerically enriched form can be classified as a chiral pool approach ${ }^{1}$, a chiral auxiliary approach $^{2}$ or a transformation from other enantio-enriched compounds, such as 1,2-diols, ${ }^{3 \mathrm{a}-}$ $\mathrm{c}_{\alpha \text {-hydroxy acids }}{ }^{3 \mathrm{~d}}$ and cyanohydrins, ${ }^{3 \mathrm{e}}$ synthesized by other enantioselective methods.

However, to our knowledge catalytic enantioselective synthesis of $\alpha$-tertiary hydroxyaldehydes directly from prochiral precursors has not been reported. ${ }^{4}$ In the course of studying palladiumcatalyzed asymmetric allylic alkylation (AAA) of simple ketone enolates, ${ }^{5}$ we postulated that treatment of enol carbonate 2 or $\mathbf{3}$ bearing a shiftable $\mathrm{OR}_{1}$ group with a proper chiral palladium catalyst presumably could regio- and enantioselectively generate $\mathrm{R}_{1}$ protected $\alpha$-tertiary hydroxyaldehydes $\mathbf{1}$ (eq. 1). Substrates $\mathbf{2}$ and $\mathbf{3}$ can be made from readily available $\alpha$-halo or $\alpha$-hydroxy ketones. ${ }^{6}$ Herein, we report the first example of a palladium catalyzed highly enantioselective synthesis of $\alpha$-tertiary hydroxyaldehydes resulting from a novel competition and demonstrated its synthetic utility in a formal synthesis of $(S)$-oxybutynin. ${ }^{7}$

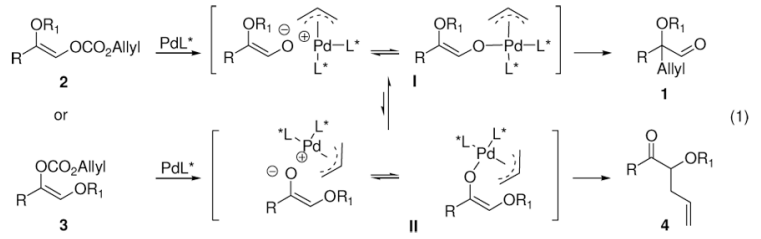

We initially subjected $\mathbf{2 a - 1}$ and $\mathbf{3 a}-\mathbf{1}$ respectively to our previously reported conditions (2.5 $\mathrm{mol} \% \mathrm{Pd}_{2}(\mathrm{dba})_{3} \mathrm{CHCl}_{3}$ and $5.5 \mathrm{~mol} \%(R, R)$-L in 1,4-dioxane at $\left.23{ }^{\circ} \mathrm{C}\right) .5$ Although the reaction of 2a-1 was significantly faster, the only product from either was aldehyde $(S)$-1a with excellent yields and ee's (Table 1 , entry 1 and 2). ${ }^{8}$ As summarized in Table 1 , the scope of the $\mathrm{R}_{1}$ group was explored. With few exceptions, the reaction favored the formation of aldehyde 1a independent of the $O$ - substituent while, in several cases, reactions with achiral ligand 1,2-bis (diphenylphosphino)ethane (dppe) as ligand the major product was ketone $\mathbf{4 a}$ (Table 1, entry 
6,8 and 10). The reaction of $\mathbf{3 a - 3}$ with a TIPS or $\mathbf{3 a - 8}$ with a mesitoyl group was slower than that with a less bulky group in the same class; in both cases a significant amount of ketone 4a was isolated (Table 1, entry 4 and 12). Presumably if the equilibrium between enolate $\mathbf{I}$ and II is faster than the allylation, the reaction should proceed through the former since it is more stable than II both electronically and sterically. On the other hand, if the rate of allylation became faster than the rate of enolate equilibration as may be occurring in the case of acetyl (Table 1, entry 7) or with dppe as ligand, then an increasing amount of ketone is observed (Table 1, entry 6, 8 and 10). Substrate 3a-9 with an un-shiftable methoxymethyl (MOM) group had very poor conversion under the same conditions, perhaps due to the chelation of the intermediate enolate with the Pd catalyst (Table 1, entry 13). Support for this contention derives from the observation that the reaction of 3a-1 was severely inhibited by the addition of an equal amount of 3a-9 (6\% conversion in contrast to a full conversion in $1 \mathrm{~h}$ in the absence of 3a-9. In addition, The $E$-enolate generated from $\mathbf{5}$ can not chelate to the catalyst and reacted readily (eq. 2).

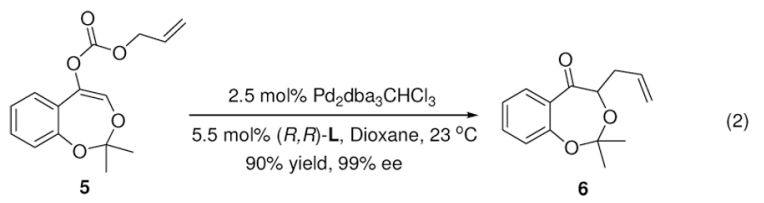

Although various $\mathrm{R}_{1}$ groups are suitable, we selected the most commonly used TBDMS as the hydroxy protecting group and investigated the scope of the nucleophilic moiety (Table 2). In general, excellent yields and ee's were obtained with R as different as aryl, alkenyl or alkynyl groups (Table 2). For substrates where R are alkenyl groups, only the $\alpha$-alkylated aldehydes are generated, no $\gamma$-alkylated enal is observed (entry 9 and 10). ${ }^{9}$ Since the silicon migration of trans enediolate is not likely as in substrate $\mathbf{1 1}$, it reacted to afford ketone $\mathbf{4 i}$ in $95 \%$ yields and 99\% ee while its cis isomer $2 \mathbf{i}$ converted to aldehyde $1 \mathbf{i}$ in $76 \%$ yield and $89 \%$ ee under the same conditions (entry 12 and 15). In the case of tetra-substituted enol carbonate 7 (entry 13), $\alpha$-tertiary siloxy ketone $\mathbf{8}$ generated from the corresponding $E$-enolate favored formation of the $R$-enantiomer. ${ }^{10}$ The reaction also works for the synthesis of a cyclic $\alpha$-tertiary siloxy ketone 10 with a moderate ee in favor of the $R$ - enantiomer (entry 14). ${ }^{11}$

Variation of the allyl moiety to cycloalkenyl as in $\mathbf{1 2}$ led to $\mathbf{1 4}$ quantitatively (eq. 3). The regioisomer $\mathbf{1 3 b}$ reacted slower than $\mathbf{1 2 b}$ but still in quantitative yield; whereas, the reaction of $\mathbf{1 3 c}$ proceeded only in $30 \%$ conversion. The dr of $\mathbf{1 4}$ increased from 2.5:1 to over 50:1 with increasing cycloalkenyl ring size. Removal of one of the stereogenic centers by hydrogenation of the $\mathrm{C}=\mathrm{C}$ double bond gave compounds $\mathbf{1 5} \mathbf{a}-\mathbf{c}(\mathrm{n}=1,2$, or 3$)$. The ee of $\mathbf{1 5}$ reflected the $\mathrm{dr}$ of 14. 15b was converted into the key intermediate $\mathbf{1 7}$ for the synthesis of $(S)$-oxybutynin in 95\% yield, wherein one recrystallization increased the ee to over 99\% (Scheme 1).

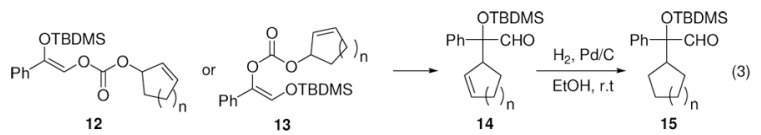

In summary, we report the first catalytic asymmetric synthesis of $\alpha$-tertiary hydroxyaldehydes by palladium catalyzed allylic alkylation of siloxy enol carbonates. The excellent selectivity towards aldehyde was achieved by using chiral ligand $\mathbf{L}$, which is in stark contrast to dppe which favors ketone formation. The reaction proceeds under very mild conditions and generates an $\alpha$-tetra-substituted stereogenic center with excellent yield and enantiomeric excess. Further investigation of the mechanism, reaction scope and its application in organic synthesis are ongoing. 


\section{Supplementary Material}

Refer to Web version on PubMed Central for supplementary material.

\section{Acknowledgement}

We thank the National Science Foundation and the National Institutes of Health, General Medical Sciences Grant GM13598, for their generous support of our programs. J. Xu has been supported by Abbott Laboratories Fellowships. Mass spectra was provided by the Mass Spectrometry Regional Center of the University of California-San Francisco supported by the NIH Division of Research Resources. We thank Chirotech (now Dow) for their generous gifts of ligands and Johnson Matthey for gifts of palladium salts.

\section{References}

1. Coppola, GM.; Schuster, HF. $\alpha$-Hydroxy Acids in Enantioselective Syntheses. Weinheim: WileyVCH; 1997.

2. Seyden-Penne, J. Chiral Auxiliaries and Ligands in Asymmetric Synthesis. New York, NY: John Wiley \& Sons; 1995. b Ruano JLG, Barros D, Maestro MC, Alcudia A, Fernández I. Tetrahedron: Asymmetry 1998;9:3445. c Tamura Y, Kondo H, Annoura H, Takeuchi R, Fujioka H. Tetrahedron Lett 1986;27:81. d Guanti G, Narisano E, Pero F, Banfi L, Scolastico C. J. Chem. Soc. Perkin Trans. 1 1984:189. e Guanti G, Narisano E. Tetrahedron Lett 1983;24:817. f Mukaiyama T. Tetrahedron 1981;37:4111.

3. Hughes, DL. Comprehensive Asymmetric Catalysis. Jacobsen, EN.; Pfaltz, A.; Yamamoto, H., editors. Vol. 3. Berlin: Springer; 1999. p. 1273 b Kolb HC, VanNieuwenhze MS, Sharpless KB. Chem. Rev 1994;94:2483. c Hof RR, Kellogg RM. J. Chem. Soc. Perkin Trans.1 1996:2051. d Ooi T, Fukumoto K, Maruoka K. Angew. Chem. Int. Ed 2006;45:3839. e Brunel JM, Holmes IP. Angew. Chem. Int. Ed 2004;43:2752.

4. Enantioseletive aldol reactions of $\alpha$-oxyaldehydes catalyzed by organocatalysts have been reported. SeeNorthrup AB, Mangion IK, Hettche F, MacMillian DWC. Angew. Chem. Int. Ed 2004;43:2152.

5. a Trost BM, Xu J. J. Am. Chem. Soc 2005;127:17180. [PubMed: 16332054] b Trost BM, Xu J. J. Am. Chem. Soc 2005;127:2846. [PubMed: 15740108]c. Similar results were reported independently by Stoltz et. al. using $t$-Bu-PHOX ligands. SeeBehenna DC, Stoltz BM. J. Am. Chem. Soc 2004;126:15044. [PubMed: 15547998]

6. See Supporting Information for the examples of the synthesis of siloxy enol carbonates.

7. a Thompson IM, Lauvetz R. Urology 1976;8:452-454. [PubMed: 790746]For the synthesis of (S)Oxybutynin see: b Tokuda O, Kano T, Gao WG, Ikemoto T, Maruoka K. Org. Lett 2005;7:5103. [PubMed: 16235968] c Gupta P, Fernandes RA, Kumar P. Tetrahedron Lett 2003;44:4231. d Masumoto S, Suzuki M, Kanai M, Shibasaki M. Tetrahedron Lett 2002;43:8647. e Grover PT, Bhongle NN, Wald SA, Senanayake CH. J. Org. Chem 2000;65:6283. [PubMed: 10987980] f Senanayake CH, Fang K, Crover P, Bakale RP, Vandenbossche CR, Wald SA. Tetrahedron Lett 1999;40:819.

8. The absolute configuration of $\mathbf{1 a}$ was determined by reduction of $\mathrm{CHO}$ to $\mathrm{CH}_{2} \mathrm{OH}$ followed by removal of TBDMS and comparison of the optical rotation of the product $1,2-\mathrm{diol}\left([\alpha]_{\mathrm{D}}{ }^{24}=-45.2\right.$ (c 1.2 , $\left.\mathrm{CHCl}_{3}\right)$ ) with the reported data for $(2 R)$-1,2-dihydroxy-2-phenylpent-4-ene $\left([\alpha]_{\mathrm{D}}{ }^{20}=+43.4(\mathrm{c} 1.2\right.$, $\mathrm{CHCl}_{3}$ )).Agami C, Couty F, Lequesne C. Tetrahedron 1995;51:4043.

9. Waetzig SR, Rayabarapu DK, Weaver JD, Tunge JA. Angew. Chem. Int. Ed 2006;45:4977.

10. The absolute configuration of $\mathbf{8}$ was determined by removal of TBDMS and comparison of the optical rotation of the product $\left([\alpha]_{\mathrm{D}}{ }^{24}=-91.3\right.$ (c 1.05, benzene)) with the reported data for $(S)$-3-hydroxy-3phenyl-hex-5-en-2-one $\left([\alpha]_{\mathrm{D}}{ }^{26}=+124.7\right.$ (c 0.635, benzene)).Soai K, Ishizaki M. J. Org. Chem 1986;51:3290.

11. The absolute configuration of $\mathbf{1 0}$ was determined by removal of TBDMS and comparison of the optical rotation of the product $\left([\alpha]_{\mathrm{D}}{ }^{23}=-73.4\left(\mathrm{c}, 2.6, \mathrm{CHCl}_{3}\right)\right)$ with the reported data for $(S)-2$ allyl-2-hydroxy-cyclohexanone $\left([\alpha]_{\mathrm{D}}=+136.6\left(\mathrm{c} 2, \mathrm{CHCl}_{3}\right)\right)$.Compain $\mathrm{P}$, Goré J, Vatèle JM. Tetrahedron 1996;52:6647. 

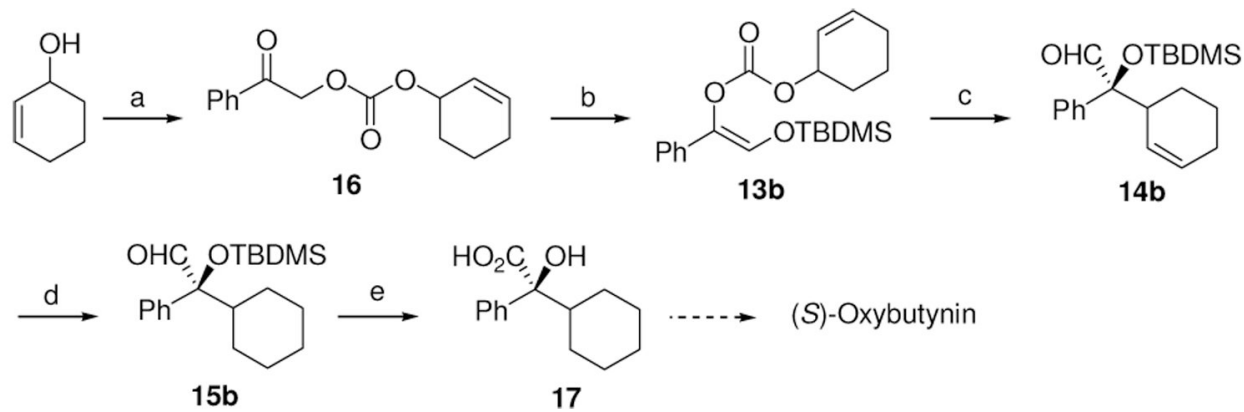

Scheme 1.

Formal Synthesis of $(S)$-Oxybutynin.a

${ }^{a}$ Reagents and conditions: (a) $\mathrm{NaH}, \mathrm{CO}_{2}$, THF, then $\mathrm{PhCOCH}_{2} \mathrm{Br}$, DMF, $23{ }^{\circ} \mathrm{C}, 42 \%$; (b)

$\mathrm{NaHMDS}$, TBSCl, THF, $-78{ }^{\circ} \mathrm{C}$ to $23{ }^{\circ} \mathrm{C}, 83 \%$; (c) $2.5 \mathrm{~mol} \% \mathrm{Pd}_{2}\left(\mathrm{dba}_{3} \mathrm{CHCl}_{3}, 5.5 \mathrm{~mol} \% \mathrm{~L}\right.$, 1,4-dioxane, $23{ }^{\circ} \mathrm{C}, 99 \%$ (dr 11:1); (d) $\mathrm{H}_{2}$, cat. $\mathrm{Pd} / \mathrm{C}$, EtOH, $23{ }^{\circ} \mathrm{C}, 96 \%, 84 \%$ ee; (e) $\mathrm{NaClO}_{2}, \mathrm{NaH}_{2} \mathrm{PO}_{4}, 2$-methyl-2-butene, $t$-BuOH, $\mathrm{H}_{2} \mathrm{O}, 23{ }^{\circ} \mathrm{C}, 95 \%$ (recrystallization from hexane/DCM, >99\% ee). 


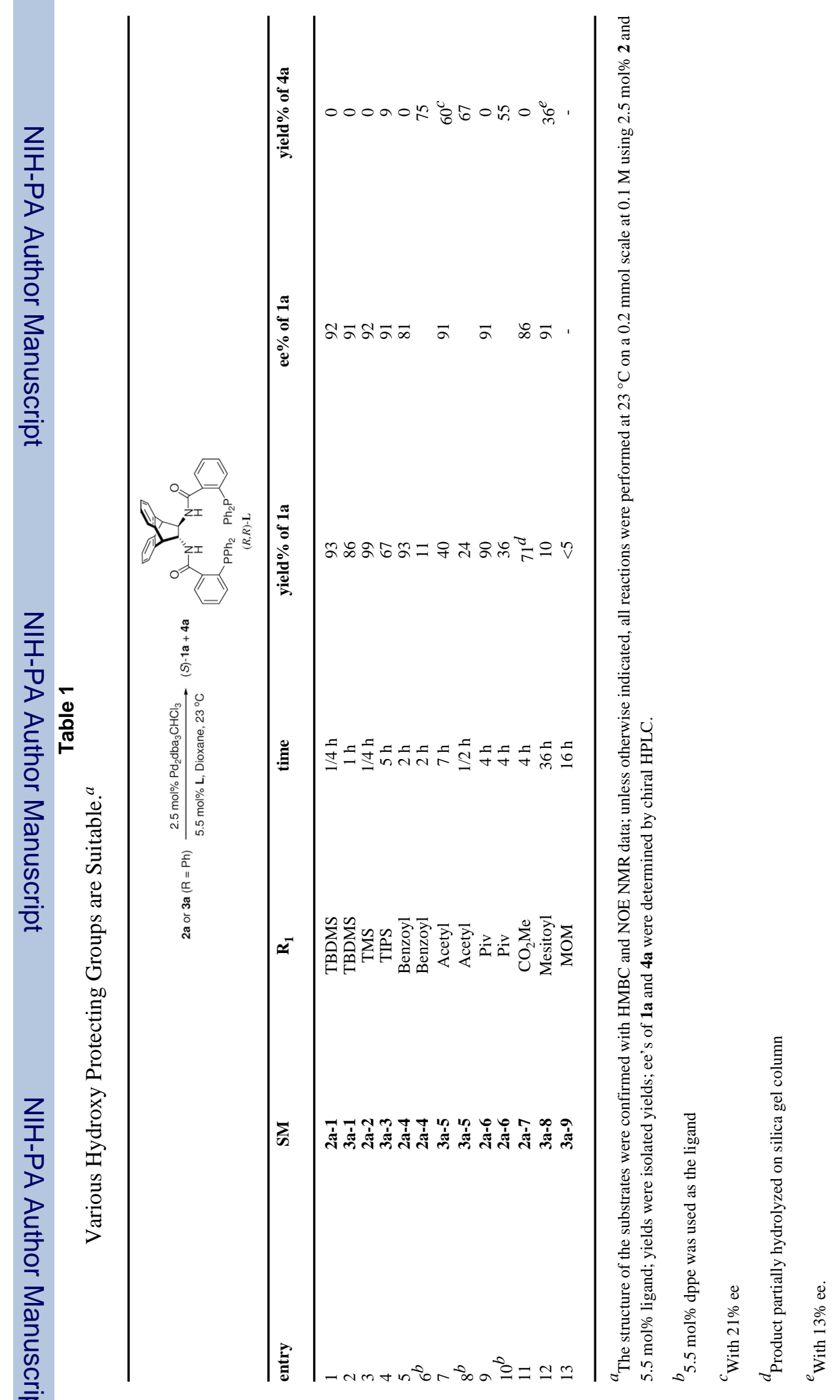

$J$ Am Chem Soc. Author manuscript; available in PMC 2008 September 11. 


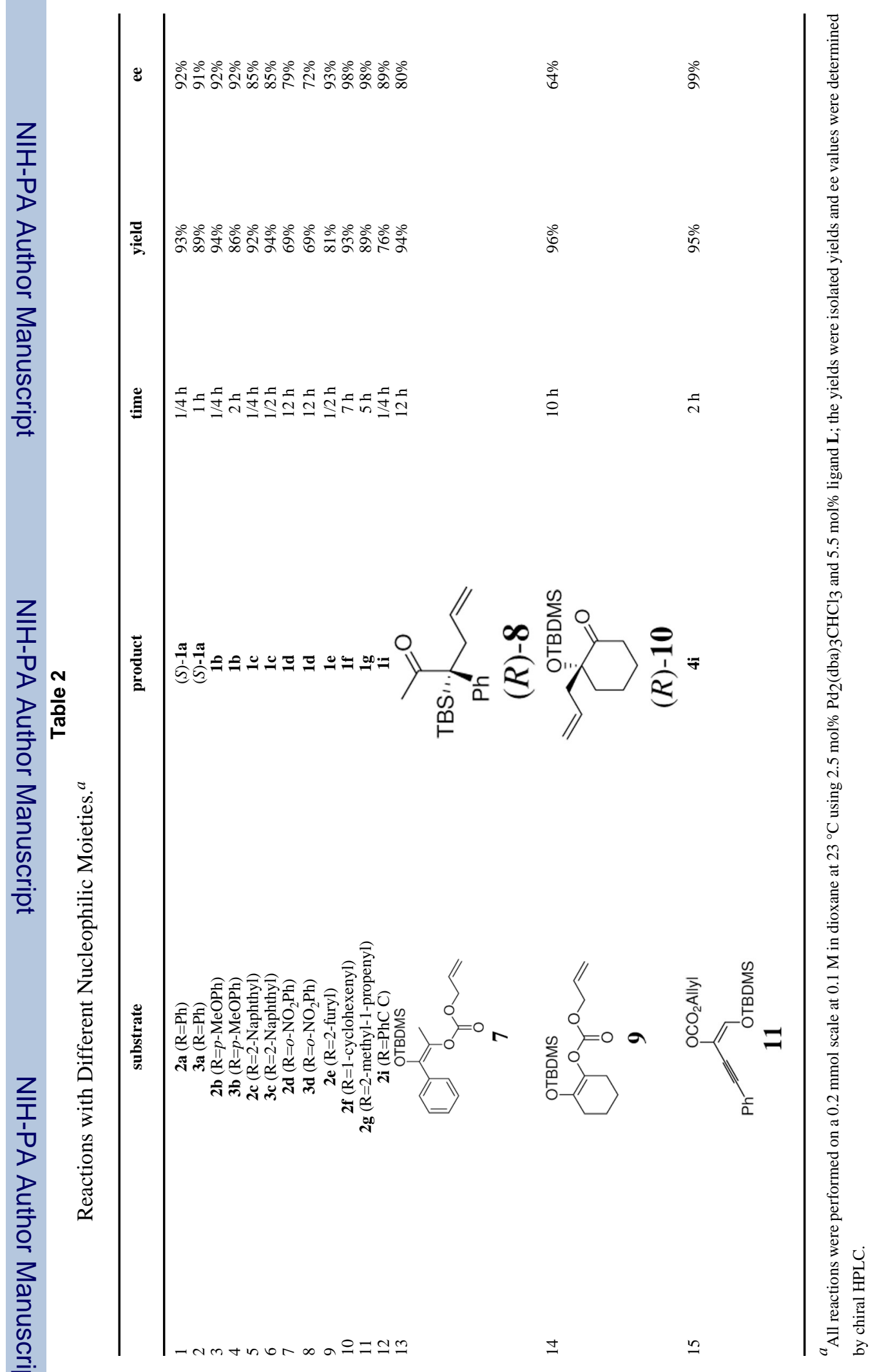




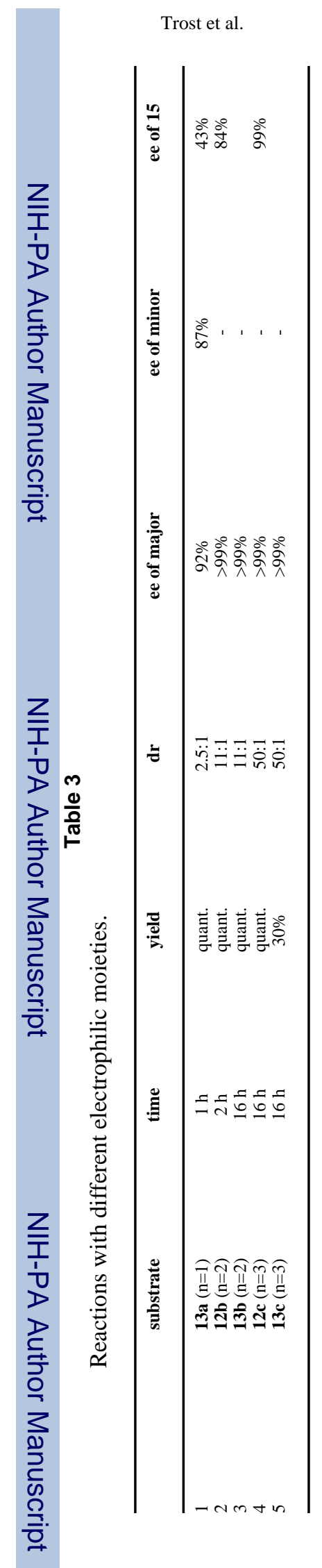

Page 7 